\title{
Avaliação do efeito antifúngico do óleo resina e do óleo essencial de copaíba (Copaifera multijuga Hayne)
}

\author{
DEUS, R.J.A.*; ALVES, C.N.; ARRUDA, M.S.P. \\ Laboratório de Química, Programa de Pós-graduação em Química, ICEN, Universidade Federal do Pará, Avenida \\ Augusto Correa, s/n-Guamá, CEP:66075-110,Belém-Brasil *dedeus@ufpa.br
}

\begin{abstract}
RESUMO: Óleo de Copaifera multijuga Hayne, in natura e as frações foram avaliados quanto às suas atividades fungitóxicas, frente a cinco espécies de fungos filamentosos do gênero Aspergillus e três espécies de leveduras do gênero Candida. Concentrações de óleo resina e de óleo essencial na faixa de $0,08 \mathrm{mg} \mathrm{mL}^{-1}$ a $1,6 \mathrm{mg} \mathrm{mL}^{-1}$ foram usadas para as análises qualitativa e quantitativas. As amostras foram dispostas sobre discos de papel de $5 \mathrm{~mm}$ de diâmetro e distribuídos sobre 0 meio Saboraud em placas de Petri, inoculadas com esporos dos microrganismos e incubadas a $28^{\circ} \mathrm{C}$ durante 10 dias. Utilizou-se uma solução com $1,6 \mathrm{mg} \mathrm{mL}^{-1}$ de nitrato de miconazol como controle positivo. Os resultados qualitativos mostraram que o óleo resina apresentou boa atividade, porém uma das frações do óleo essencial se mostrou altamente efetivo contra $C$. parapsilosis IOC - 2882, A.flavus IOC-3874 e A. tamarii IOC-187 com halos de inibição de 16,0 $11,4 \mathrm{~mm}$, $19,5 \pm 2,1 \mathrm{~mm}$ e $12,5 \pm 3,5 \mathrm{~mm}$, respectivamente. Já a avaliação quantitativa mostrou que $0,3 \mathrm{mg}$ $\mathrm{mL}^{-1}$ do óleo resina inibiu o crescimento de $A$. flavus e $C$. parapsilosis, enquanto que $0,08 \mathrm{mg}$ $\mathrm{mL}^{-1}$ da fração do óleo essencial atingiu esta mesma atividade.
\end{abstract}

Palavra-chave: Copaifera multijuga, óleo essencial, atividade antifúngico, Aspergillus, Candida

\begin{abstract}
ABTRACT: Evaluation of the antifungal effect of oleoresin and essential oil of copaiba (Copaifera multijuga Hayne). Copaifera multijuga Hayne oil in natura and its fractions were evaluated as to their fungitoxic activities against five filamentous fungus species belonging to the genus Aspergillus and three yeast species of the genus Candida. Oleoresin and essential oil concentrations ranging from $0.08 \mathrm{mg} \mathrm{mL}^{-1}$ to $1.6 \mathrm{mg} \mathrm{mL}^{-1}$ were used for qualitative and quantitative analyses. The samples were placed onto $5 \mathrm{~mm}$-diameter paper discs distributed on Sabouraud's medium in Petri dishes inoculated with spores of the microorganisms and incubated at $28^{\circ} \mathrm{C}$ for 10 days. A solution containing $1.6 \mathrm{mg} \mathrm{mL}^{-1}$ miconazole nitrate was used as positive control. Qualitative results showed that the oleoresin presented good activity, while a fraction of the essential oil was highly effective against Candida parapsilosis IOC-2882, Aspergillus flavus IOC-3874 and A tamarii IOC-187 with $16.0 \pm 1.4 \mathrm{~mm}, 19.5 \pm 2.1 \mathrm{~mm}$ and $12.5 \pm 3.5 \mathrm{~mm}$ inhibition halos, respectively. The quantitative evaluation showed that $0.3 \mathrm{mg} \mathrm{mL}^{-1}$ oleoresin inhibited the growth of Aspergillus flavus and Candida parapsilosis, while $0.08 \mathrm{mg} \mathrm{mL}^{-1}$ of the essential oil fraction reached this same activity.
\end{abstract}

Key words: Copaifera multijuga, essential oil, antifungal activity, Aspergillus, Candida

\section{INTRODUÇÃO}

Diversas doenças microbianas de origens bacteriana, viral ou fúngica são relatadas na literatura. Em muitos casos, os responsáveis pelas infecções adquirem resistência ao medicamento administrado, e por este motivo grande número de antibióticos tem sido desenvolvido (Kubo et al., 1993; Koshi \& Cherian, 1995). Paralelamente, a busca de antimicrobianos

\begin{abstract}
de origem natural que apresentem atividade sobre grande espectro de microrganismo e que possam ser usados como alternativa aos antibióticos convencionais tem despertado o interesse da classe científica, sobretudo nas moléculas de origem vegetal, já que as plantas possuem grande potencial em sintetizar substancias químicas com estruturas diversificadas,
\end{abstract}


como sistema de defesa contra agentes patogênicos (Rodrigues et al., 1997). Para serem efetivas como agentes antimicrobianos, as substâncias precisam ser produzidas e acumuladas em concentrações suficientes nos órgãos e sítios intracelulares, e se são efetivas em tecidos vegetais poderão ser efetivas em tecidos animais (Santos, 1998). Este assunto vem ao encontro da investigação sistemática sobre os aspectos microbiológicos, profiláticos e terapêuticos das infecções oportunistas (Rodrigues et al., 1997). Dentro deste assunto, ressaltam-se as infecções fúngicas que correspondem até $10 \%$ do total de casos, com predomínio de microrganismo pertencente aos gêneros Candidae Aspergillus (Koshi \& Cherian, 1995; Mylonakis \& Calderwood, 2001).

O principal tratamento para a infecção fúngica é a antibioticoterapia endovenosa prolongada (Verghese et al., 1998; Menesalvas \& Bouza, 1998). O tratamento específico de doenças causadas por fungos é prolongado em função da dificuldade diagnóstica mais do que às infecções causadas por bactérias; fato este que limita o arsenal antimicrobiano contra este tipo de patógeno. Deste modo, a busca de antimicrobianos de origem vegetal se apresenta com grande potencial em função das células vegetais reagirem contra patógenos, além de que possam ser mais eficientes no tratamento dessas infecções micóticas e menos tóxicas aos pacientes (Recio et al., 1989; Farnsworth, 1996).

Entre as diversas famílias de plantas estudadas, destaca-se a Leguminosae que está divida em três subfamílias, Caesalpinoideae, Mimosoideae e Papilionoideae (ou Faboideae) (Judd et al.,1999). Nesta classificação, destaca-se o gênero Copaifera, pertencente à subfamília Caesalpinoideae (Andrade Junior et al., 2000; Veiga Junior \& Pinto, 2002), gênero que apresenta 16 espécies ocorrentes no Brasil das quais apenas 4 ocorrem na região Norte, onde o óleo de copaíba é amplamente comercializado e utilizado na medicina popular (Cascon \& Gilbert, 2000).

O óleo de copaíba é constituído de dois grupos de substâncias distintas, solúveis entre si, sendo um constituído de substâncias voláteis, correspondendo a cerca de $90 \%$ de massa do óleo resina e outro grupo constituído de substâncias não voláteis, resinosa de cor caramelo que começa a ser decomposta à temperatura próxima de $300^{\circ} \mathrm{C}$, e que corresponde a $10 \%$ da massa total do óleo resina (Veiga Junior, 1997).

Neste trabalho, descrevem-se as avaliações dos potenciais antifúngicos do óleo resina e do óleo essencial de copaíba, comparando-se os níveis de fungitoxidade dos óleos naturais com o nitrato de miconazol, um fungicida comercial, frente a 5 espécies de fungos filamentos do gênero Aspergillus e 3 espécies de leveduras do gênero Candida.

\section{MATERIAL E MÉTODO}

\section{Coleta do óleo resina de copaíba}

O óleo resina de copaíba foi coletado no município de Santarém pertencente à mesorregião do Baixo Amazonas e à microrregião Santarém, situado à latitude 0225'30"S, longitude 54ㄴ2'50"W. A espécie foi identificada como Copaifera multijuga Hayne apresentando registro de exsicata de número INPA-82418 depositado no herbário do Instituto Nacional de Pesquisas da Amazônia (INPA).

Para obtenção do óleo, foi usado trado manual de 7/8 polegada de diâmetro e $1,0 \mathrm{~m}$ de comprimento. A árvore foi perfurada à altura de 60 a $70 \mathrm{~cm}$ do chão, até o centro do caule (20 a $50 \mathrm{~cm}$ de profundidade no tronco, conforme o diâmetro da árvore), com pequeno declive para escoamento. Uma mangueira de $3 / 4$ de polegada foi colocada bem ajustada no orifício, e no outro extremo do tubo foi colocado frasco de vidro âmbar de $1 \mathrm{~L}$. Após a colheita, o furo foi tampado com uma espécie de rolha de madeira ou com argila e a árvore foi preservada recebendo curativo. Este método produz pouco óleo, tem altos custos operacionais, mas preserva a árvore, para colheitas futuras e é ecologicamente correto (Azevedo, 2004).

\section{Obtenção das linhagens de fungos utilizados nos ensaios}

As cepas de microrganismos das espécies Aspergillus flavus (IOC-3974), Aspergillus niger (IOC200), Aspergillus tamarii (IOC-186), Aspergillus tamarii (IOC-187), Aspergillus terreus (IOC-217), Candida guilliermondii (IOC-2889), Candida tropicallis (IOC3610) e Candida parapsilosis (IOC-2882), empregadas neste trabalho foram obtidas do Laboratório de Coleção de Fungos do Instituto Osvaldo Cruz (Fiocruz-RJ).

\section{Meio de cultura e cultivo dos microrganismos}

O meio de cultura utilizado para este experimento foi o ASD (Ágar Sabouraud-Dextrose). Em cada placa de Petri foram adicionados $20 \mathrm{~mL}$ de meio (Midley et al., 1998; Mendes-Giannini \& Melhem, 2001; Minami, 2003). O método de investigação de atividade fungitóxico aplicado neste trabalho foi adaptado e segue um protocolo de execução do descrito por Lima et al.(2006).

\section{Obtenção do óleo essencial}

$100 \mathrm{~mL}$ do óleo resina de copaíba foram submetidos à destilação em balão de fundo redondo de $250 \mathrm{~mL}$, no qual foram adaptados a coluna de destilação de $30 \mathrm{~cm}$ de comprimento por $2 \mathrm{~cm}$ de diâmetro e condensador de $40 \mathrm{~cm}$ de comprimento com $1 \mathrm{~cm}$ de diâmetro de serpentina no qual foi acoplada refrigeração com circulação de água com vazão de $4 \mathrm{~L}$ por min a temperatura de $10^{\circ} \mathrm{C}$. $\mathrm{O}$ procedimento foi realizado durante $5 \mathrm{~h}$, obtendo-se 
$75 \mathrm{~mL}$ de destilado, os quais foram transferidos para frasco de vidro de cor âmbar, hermeticamente fechado e armazenado em temperatura de $5^{\circ} \mathrm{C}$ para uso posterior (Veiga Junior \& Pinto, 2002).

\section{Preparo do inóculo}

$\mathrm{O}$ inoculo dos diferentes microrganismos descritos foram preparados através do cultivo em tubos de ensaio de $15 \mathrm{~cm} \times 1,5 \mathrm{~cm}$ com tampa, contendo $5 \mathrm{~mL}$ de meio de cultura na posição inclinada e incubados a $28^{\circ} \mathrm{C}$, durante 7 dias. Após este período, adicionou-se $3 \mathrm{~mL}$ de água estéril com subsequente agitação em Vortex (QUIMIS-220A) durante $1 \mathrm{~min}$. As suspensões de esporos (na faixa de $10^{6}$ a $10^{8}$ esporos $\mathrm{mm}^{-1}$ ) foram transferidas para frascos com tampas e mantidas sob refrigeração a temperatura de $10^{\circ} \mathrm{C}$ para uso posterior como inóculo (Naghetini, 2006).

\section{Análise do óleo de copaíba via CG/EM}

CG/EM: o óleo resina e o essencial foram analisados por Cromatografia de Gás (Focus GC) acoplado a um Espectrometro de Massas em sistema Thermo DSQII, com coluna capilar de sílica OV-5 (30 $\mathrm{m} \times 0,25 \mathrm{~mm} ; 0,25 \mu \mathrm{m}$ de espessura do filme). A programação de temperatura foi de $60^{\circ} \mathrm{C}-240^{\circ} \mathrm{C}\left(3^{\circ} \mathrm{C}\right.$ $\min ^{-1}$ ); He foi utilizado como gás de arraste a uma velocidade linear de $32 \mathrm{~cm} \mathrm{~s}^{-1}$, medidas a $100^{\circ} \mathrm{C}$. A injeção foi do tipo "splitless"; com volume de $0,1 \mu \mathrm{L}$ de uma solução de $2 \mu \mathrm{L}$ do óleo em $1000 \mu \mathrm{L}$ de hexano (Luz et al., 1981; Santos et al., 1998; Adams, 2001).

Os espectros de massas foram obtidos por impacto eletrônico a $70 \mathrm{eV}$ com temperatura da fonte de íons a $200^{\circ} \mathrm{C}$. A identificação foi realizada por comparação de cromatograma, índice de retenção ou índice de Kovatz com dados da literatura (Luz et al., 1981; Santos et al., 1998; Adams, 2001).

\section{Determinação qualitativa da atividade antifúngica do óleo resina e do óleo essencial de copaíba.}

Aplicando a técnica de Atividade Sobre Camada Microbiana (ASCM) adaptado da técnica de difusão em Agar, onde um swab foi embebido na suspensão de esporos efetuando-se o espalhamento do microrganismo sobre a superfície do meio sólido, de modo a se obter um tapete fúngico (Apisariyakul et al.,1995; Rios et al., 1998; Brandão, 2004). Logo após a inoculação foram dispostos, sobre o meio de cultura, 6 discos de papel de filtro whatman oo $1 \mathrm{com}$ diâmetro de $5 \mathrm{~mm}$. Os discos 1, 2 e 3 continham 2 $\mu \mathrm{L}$ de óleo resina, cada. Os discos 4 e 5 continham $2 \mu \mathrm{L}$ de soluções comercial de miconazol nas concentrações de $1,6 \mathrm{mg} \mathrm{mL}^{-1}$. O disco 6 continha apenas água destilada. Procedimento idêntico foi realizado para cada microrganismo e repetido para o óleo essencial. As placas foram incubadas a $28^{\circ} \mathrm{C}$ durante 10 dias e observadas a cada 24 horas (Lima et al., 2006).

\section{Determinação quantitativa da atividade antimicrobiana do óleo resina e do óleo essencial de copaíba}

Em tubos de ensaio estéreis de $12 \mathrm{~cm} \times 1,5$ $\mathrm{cm}$ foram adicionados $500 \mu \mathrm{L}$ de Tween-80 e $5 \mathrm{~mL}$ de água desionizada, efetuando-se a homogeneização da mistura por agitação manual. A seguir, foram transferidas quantidades programadas de óleo resina ou óleo essencial de copaíba a fim de se obter suspensões nas concentrações de: $1,6 \mathrm{mg} \mathrm{mL}^{-1}, 1,4$ $\mathrm{mg} \mathrm{mL}^{-1}, 1,3 \mathrm{mg} \mathrm{mL}^{-1}, 1,1 \mathrm{mg} \mathrm{mL}^{-1}, 0,9 \mathrm{mg} \mathrm{mL}^{-1}, 0,8$ $\mathrm{mg} \mathrm{mL}^{-1}, 0,6 \mathrm{mg} \mathrm{mL}^{-1}, 0,5 \mathrm{mg} \mathrm{mL}^{-1}, 0,3 \mathrm{mg} \mathrm{mL}^{-1}, 0,1$ $\mathrm{mg} \mathrm{mL}^{-1}$ e $0,08 \mathrm{mg} \mathrm{mL}^{-1}$. A partir destas suspensões foram retiradas alíquotas de $2 \mu \mathrm{L}$ e inoculadas de acordo com o procedimento anterior. As placas foram incubadas durante 10 dias a $28^{\circ} \mathrm{C}$ e observada a formação dos halos a cada $24 \mathrm{~h}$. Os ensaios foram realizados em triplicata (Lima et al., 2006).

\section{RESULTADO E DISCUSSÃO}

\section{Avaliação do efeito fungitóxico}

Quanto aos efeitos fungitóxicos do óleo resina e do óleo essencial de Copaífera multijuga Hayne, sobre a germinação de esporos das cepas de A. flavus, A. niger, A. tamarii, A. tamarii, A. terreus, e nas divisões das células de $C$. guilliermondii, $C$. tropicallis e C. parapsilosis, observou-se a formação de tapete fúngico contínuo sobre todas as placas sendo visualizada a formação de halos em torno dos discos de papel contendo, tanto o óleo essencial quanto o óleo resina. Os resultados foram comparados com o nitrato de miconazol nas mesmas condições que as amostras, com concentração mínima de 1,6 $\mathrm{mg} \mathrm{mL}^{-1}$, o que corresponde a $32 \mu \mathrm{g}$ de óleo essencial por disco de papel. Neste estudo, observou-se que o método comumente utilizado para avaliar a ação de óleos e extratos vegetais é o de difusão em disco. Porém, esse método é padronizado pela NCCL (National Committee for Clinical Laboratory Standards) e desenvolvido para analisar agentes antimicrobianos (Nascimento et al., 2007).

O halo formado ao redor da amostra contendo o óleo resina se formou com um diâmetro mínimo de $7 \mathrm{~mm}$, ou seja $30 \%$ menor que o halo formado com a amostra contendo miconazol. Este resultado ressalta a presença da atividade em 8 dias para as Candida, porém a partir deste período a atividade declinou havendo o avanço microbiano sobre a zona inibida. Por este motivo, e com base nas observações, o óleo resina desta espécie apresentou apenas atividade fungistática para as leveduras. Já para nos fungos filamentosos, os 
halos de inibição foram maiores demonstrado que estes microrganismos são menos tolerantes ao óleo resina do que as leveduras (Tabela 1).

O óleo essencial apresentou halo de inibição com diâmetro de $19,5 \mathrm{~mm}$, maior $25 \%$ do que o halo de inibição produzido pelo nitrato de miconazol (controle positivo). Neste contexto, observou-se que a formação do halo se manteve apenas por 8 dias para todas as linhagens, permitindo afirmar que o óleo essencial apresenta atividade fungistática, porém 0 óleo essencial apresentou atividade superior ao óleo resina, principalmente frente $A$. flavus e $C$. parapsilosis, possivelmente, causada pelo aumento nas concentrações de $\alpha$-copaeno (Tabela 2) (Koshi \& Cherian, 1995; Mylonakis \& Calderwood, 2001). O óleo resina de copaíba apresentou densidade de $0,8466 \mathrm{mg} \mathrm{mL}^{-1}$, propriedade que foi usada para a conversão de volume em massa. O valor da densidade encontrado está dentro da faixa descrita na literatura para óleo resina (Shanley et al., 1998).

As composições químicas voláteis do óleo resina e do óleo essencial foram analisadas por cromatografia gasosa acoplada a espectrometria de massas (CG-EM), nas quais se observou as presenças de 23 constituintes no óleo resina e 7 constituintes no óleo essencial, ressaltando-se variações modestas nas concentrações de poucos constituintes, e variações mais significativas para $\alpha$ copaeno, óxido-de-cariofileno e $\beta$-cariofileno (Tabela 2 ). Desta forma, se supôs que as substancias químicas: $\alpha$-copaeno, $\beta$-cariofileno, Trans- $\alpha$ bergamoteno, $\alpha$-humuleno, $\gamma$-muuroleno e $\beta$ bisaboleno, fossem responsáveis pela inibição microbiana no óleo resina (Craveiro et al., 1981; Wang, 2000; Souza et al., 2005). Nestas condições, a inibição do crescimento microbiano foi mais efetiva com óleo essencial do que com o óleo resina.

Em relação à ação do Nitrato de Miconazol, avaliado nas mesmas condições experimentais dos óleos, verificou-se que o óleo resina ou o óleo essencial de copaíba não apresentaram diferenças significativas de atividade para os microrganismos $A$. niger (IOC- 200) e A. tamarii (IOC-186), o que mostra efetividade das amostras contra os microrganismos avaliados. Resultados mais significativos foram obtidos com as cepas de Aspergillus flavus (IOC3974), Aspergillus tamarii (IOC-187) e Candida parapsilosis (IOC-2882) que apresentaram halos de inibição maiores do que a do miconazol, o que sugeriu caracterizar o óleo essencial da espécie de Copaifera

TABELA 1. Resultados dos halos de inibição do crescimento de fungos frente ao efeito antifúngico do óleo resina e do óleo essencial de copaíba.

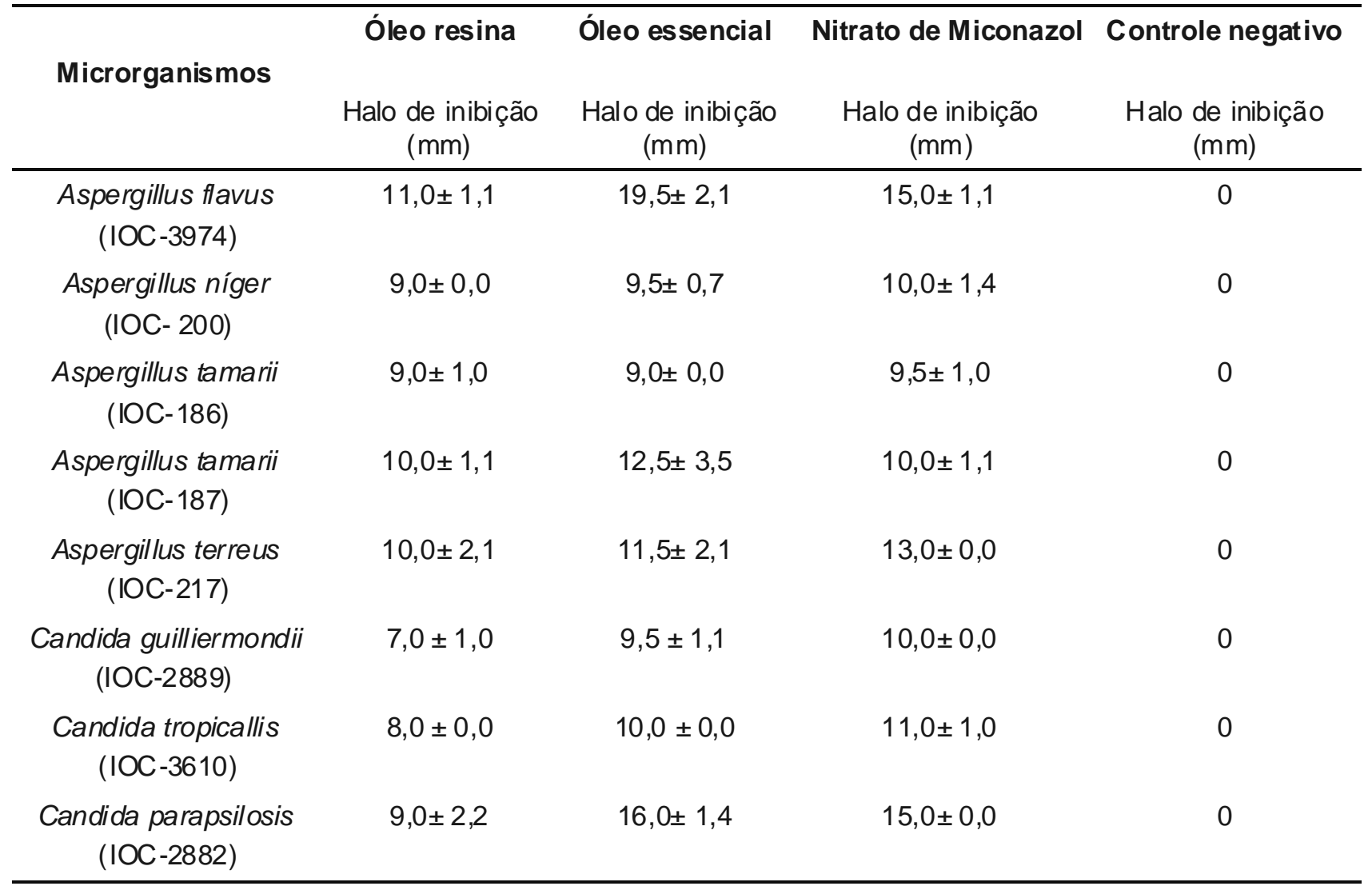

Concentração de óleo resina $1,6 \mathrm{mg} \mathrm{mL}^{-1}$ (32 $\mu \mathrm{g}$ de óleo por disco) Concentração de óleo essencial 1,6 mg mL-1 Concentração de nitrato de miconazol 1,6 mg mL-1 Controle negativo: solução de água + tween-80

Rev. Bras. PI. Med., Botucatu, v.13, n.1, p.1-7, 2011. 
TABELA 2. Composições químicas do óleo resina e óleo essencial de Copaifera multijuga Hayne.

\begin{tabular}{|c|c|c|c|c|c|}
\hline Pico & IR & IK & $\begin{array}{l}\text { Componentes } \\
\text { químicos }\end{array}$ & $\begin{array}{l}\text { Conc. no } \\
\text { Óleo resina } \\
(\%)\end{array}$ & $\begin{array}{c}\text { Conc. na } \\
\text { Fração do óleo } \\
\text { essencial } F_{10}(\%)\end{array}$ \\
\hline 1 & 20.57 & 1339 & ס-elemeno & 0,38 & - \\
\hline 2 & 21.09 & 1352 & a-cubebeno & 0,26 & - \\
\hline 3 & 22.19 & 1382 & a-copaeno & 3,04 & 3,29 \\
\hline 4 & 22.82 & 1391 & $\beta$-elemeno & 0,9 & - \\
\hline 5 & 23.12 & 1409 & a-gurjuneno & 0,19 & - \\
\hline 6 & 24.20 & 1426 & $\beta$-cariofileno & 67,07 & 57,29 \\
\hline 7 & 24.67 & 1436 & Trans- $\alpha$-bergamoteno & 6,08 & 5,31 \\
\hline 8 & 24.92 & 1442 & $\mathrm{NI}$ & 0,25 & - \\
\hline 9 & 25.35 & 1457 & a-humuleno & 10,87 & 9,11 \\
\hline 10 & 25.52 & 1461 & allo-aromadendreno & 0,33 & - \\
\hline 11 & 26.35 & 1477 & Y-muuruleno & 3,27 & 1,63 \\
\hline 12 & 27.10 & 1499 & a-muuruleno & 0,75 & - \\
\hline 13 & 27.47 & 1509 & $\beta$-bisaboleno & 1,43 & 1,08 \\
\hline 14 & 28.02 & 1524 & $\bar{\delta}$-cadineno & 1,34 & - \\
\hline 15 & 28.31 & 1542 & $\mathrm{NI}$ & 0,1 & - \\
\hline 16 & 28.75 & 1554 & $\mathrm{NI}$ & 0,12 & - \\
\hline 17 & 29.68 & 1562 & $\mathrm{NI}$ & 0,62 & - \\
\hline 18 & 30.15 & 1581 & Óxido de cariofileno & 0,64 & 10,34 \\
\hline 19 & 31.45 & 1595 & $\mathrm{NI}$ & 0,11 & - \\
\hline 20 & 31.88 & 1625 & $\mathrm{NI}$ & 0.1 & - \\
\hline 21 & 32.20 & 1645 & a-muurolol & 0,57 & - \\
\hline 22 & 32.53 & 1691 & juniper cânfora & 0,6 & - \\
\hline 23 & 32.81 & 1700 & Acetato de cariofileno & 0,3 & - \\
\hline
\end{tabular}

IR- índice de retenção. (-) concentrações abaixo do limite de detecção instrumental de $0,08 \%$. (NI) não identificado IK- índice Kovatz

multijuga Hayne como agente potencial de atividade fungitóxica contra estes microrganismos (Koshi \& Cherian, 1995; Mylonakis \& Calderwood, 2001).

\section{Avaliação da Concentração Inibitória Mínima} (CIM) do óleo resina e do óleo essencial de copaíba

A Concentração Inibitória Mínima (CIM) necessária para inibir o crescimento de $A$. flavus foi de $0,08 \mathrm{mg}$ de óleo essencial por $L$ de solução, o que corresponde a $0,16 \mu \mathrm{g}$ de óleo, já que as densidades tanto do óleo resina quanto do óleo essencial não apresentaram grandes diferenças. Nestas condições se confirmou que a cepa de Aspergillus flavus foi mais suscetível a inibição do que as demais cepas analisadas, já que não existe consenso acerca do nível aceitável (Oliveira et al., 2006) . A diferença de inibição entre o óleo resina e a fração obtida (Tabela 3), indica a importância da destilação fracionada para atividade antimicrobiana, de acordo com o procedimento executado. Esta ação promoveu minimização de interferência de outras substâncias químicas presentes no óleo resina de copaíba, além de reduzir o número de variáveis para se identificação as substâncias responsáveis pela atividade avaliada (Craveiro et al., 1981; Wang, 2000; Souza et al., 2005). Por outro lado, a técnica de Atividade Sobre Camada Microbiana mostrou-se eficiente para substâncias solúveis em água possibilitando difusão destas através do meio de cultura e consequentemente, resultados satisfatórios. 
TABELA 3. Resultado da avaliação da concentração inibitória mínima (CIM) para o óleo resina e para a fração do óleo essencial de Copaifera multijuga Hayne sobre a germinação de esporos dos microrganismos.

\begin{tabular}{|c|c|c|c|c|}
\hline $\begin{array}{l}\text { Microrganismos } \\
\text { (Fio cruz-RJ) }\end{array}$ & $\begin{array}{c}\text { Óleo } \\
\text { resina } \\
\left(\mathrm{mg} \mathrm{mL}^{-1}\right)\end{array}$ & $\begin{array}{c}\text { Óleo } \\
\text { essencial } \\
\left(\mathrm{mg} \mathrm{mL}^{-1}\right)\end{array}$ & $\begin{array}{c}\text { Nitrato de Miconazol } \\
\text { (controle positivo) } \\
\left(\mathrm{mg} \mathrm{mL}^{-1}\right)\end{array}$ & $\begin{array}{l}\text { Controle } \\
\text { negativo }\end{array}$ \\
\hline $\begin{array}{l}\text { Aspergillus flavus } \\
\text { (IOC-3974) }\end{array}$ & 0,3 & $0,08^{*}$ & $0,1^{*}$ & - \\
\hline $\begin{array}{l}\text { Aspergillus níger } \\
\text { (IOC- 200) }\end{array}$ & 0,6 & 0,1 & 0,3 & - \\
\hline $\begin{array}{l}\text { Aspergillus tamarii } \\
\text { (IOC-186) }\end{array}$ & 0,6 & $0,5^{\star *}$ & 0,3 & - \\
\hline $\begin{array}{l}\text { Aspergillus tamarii } \\
\text { (IOC-187) }\end{array}$ & 0,6 & 0,3 & 0,3 & - \\
\hline $\begin{array}{l}\text { Aspergillus terreus } \\
\text { (IOC-217) }\end{array}$ & 0,5 & 0,3 & 0,1 & - \\
\hline $\begin{array}{c}\text { Candida guilliermondii } \\
\text { (IOC-2889) }\end{array}$ & 0,6 & 0,1 & 0,3 & - \\
\hline $\begin{array}{l}\text { Candida tropical lis } \\
\qquad(\mathrm{IOC}-3610)\end{array}$ & 0,6 & $0,5^{\star *}$ & $0,5^{\star *}$ & - \\
\hline $\begin{array}{c}\text { Candida parapsilosis } \\
\text { (IOC-2882) }\end{array}$ & 0,3 & 0,1 & 0,1 & - \\
\hline
\end{tabular}

(-) sem interferência na germinação dos esporos. *halo com 2mm, **halo com 3mm $16 \mu$ g por disco

\section{CONCLUSÃO}

Quanto à atividade antimicrobiana observada para o óleo resina e óleo essencial de Copaifera multijuga Hayne durante os oito dias se supõe que ou os microrganismos estão degradando as substâncias inibitórias, o que é pouco provável, ou as mesmas estão se difundindo no ar por volatilização, fenômeno que permitiu a minimização do efeito tóxico no meio de cultura, fazendo com que os microrganismos pudessem se desenvolver após 0 período de 8 dias. Esta proposição se baseia no fato de que o período foi o mesmo, tanto para as leveduras quanto para os fungos filamentosos. De um modo mais específico, a inibição dos microrganismos do gênero Aspergillus e Candida é extremamente promissora, em virtude dos valores de inibição terem atingido índices acima de $90 \%$, indicando que a fração $\mathrm{F}_{10}$ apresenta potencial de uso como agente fungistático no período de 8 dias, nas condições supradescritas. A relevância dos resultados é devida aos valores de halo de inibição encontrados para a fração $F_{10}$ serem superiores ao Nitrato de Miconazol, que foi utilizado como controle positivo. Conclusão, índices iguais ou maiores do que $85 \%$ apresentam bom potencial de ação antimicrobiana para usos práticos, razão pela qual nos permite afirmar que o óleo essencial de Copaifera multijuga Hayne poderá ser um bom indicativo para estudos mais específicos nos combates à aspergilose ou candidiase.

\section{REFERÊNCIA}

ADAMS, R.P. Identification of essential Oil Components by Gas Chromatography/Quadrupole Mass Spectroscopy. Carol Stream, Illinois: Allured Publishing Corporation, 2001. 456p.

ANDRADE JUNIOR, M.A. et al. Distribuição geográfica e aspectos de identificação taxonômica de Copaifera officinalis L. (Caesalpiniaceae), com inclusão de registros de ocorrência de Copaifera spp. em Roraima. In: CONGRESSO NACIONAL DE BOTÂNICA, 51. 2000, Brasília. Anais... Brasília: Sociedade Botânica do Brasil, 2000. p.152-2.

APISARIYAKUL, A.; VANITTANAKOM, M.; BUDDHASUKH, $D$. Antifungal activity of turmeric oil extracted from Curcuma longa (Zingiberaceae). Journal of Ethnopharmacology, v.49, p.163-9, 1995.

AZEVEDO, O.C.R. Copaíba: estrutura populacional, produção e qualidade do óleo-resina em populações nativas do sudoeste da Amazônia. 2004. 87p. Dissertação (Mestrado - Área de concentração em Ecologia e Manejo de Recursos Naturais) - Centro de Pesquisa Agroflorestal, Universidade Federal do Acre, Rio Branco.

BRANDÃO, G.C. Isolamento biomonitorado de substâncias antimicrobianas de Polygonum spectablil 
Mart e determinação da CIM para uma chalcona antimicrobiana. 2004. 194p. Dissertação (Mestrado em Ciências Farmacêuticas) - Faculdade de Farmácia, Universidade Federal de Minas Gerais, Belo Horizonte. CASCON, V.; GILBERT, B. Characterization of the chemical composition of oleoresins of Copaifera guianensis Desf., Copaifera duckei Dwyer and Copaifera multijuna Hayne. Phytochemistry, v.55, p.773-8, 2000.

CRAVEIRO, A.A. et al. Óleos essenciais de plantas do nordeste. Fortaleza: Editora UFC, 1981. 210p.

FARNSWORTH, N.R. Biological and phytochemical screening of plants. Journal Pharmaceutical Science, v.55, n.3, p.225-76, 1996.

JUDD, W.S. et al. Plant systematics: a phylogenetic approach. Sunderland: Sinauer Associates, 1999. 464p. KOSHI, G.; CHERIAN, K.M. Aspergillus terreus, an uncommon fungus causing aortic root abscess and pseudoaneurysm. Indian Heart Journal, v.47, p.265-7, 1995.

KUBO, I.; MUROI, H.; HEMIJIMA, M. Combination effects of aqnifungal nagilactones against Candida albicans and two oyher fungi with phenylpropanoids. Journal Natural Products, v.56, p.220-6, 1993.

LIMA, I.O. et al. Atividade antifúngica e óleos essenciais sobre espécies de Candida. Revista Brasileira Farmacognosia, v.16, n.2, p.197-201, 2006.

LUZ, A.I.R. et al. 1. Óleos essenciais, oleaginosas e lattices da Amazônia, 2. Estudo químico comparativo e cinética de auto-oxidação dos óleos essenciais de diferentes espécies de copaiba. In: REUNIÃO ANUAL DA SOCIEDADE BRASILEIRA PARA PROGRESSO DA CIÊNCIA, 33., 1981, Salvador. Anais... Salvador: Sociedade Brasileira para Progresso da Ciência, 1981. MENDES-GIANNINI, M.J.S.; MELHEM, M.S.C. Infecções Fúngicas. In: FERREIRA, A.W.; ÁVILA, S.L.M. Diagnóstico laboratorial das principais doenças infecciosas e autoimunes. 2.ed. Rio de Janeiro: Guanabara-Koogan, 2001. p.334-403.

MENESALVAS, A.; BOUZA, E. Infective endocarditis caused by unusual microorganisms. Revista Española de Cardiología, v.51, p.79-85, 1998.

MIDLEY, G.; CLAYTON, Y.M.; HAY, R.J. Micologia Médica: Diagnóstico em Cores. São Paulo: Manole, 1998. 86p. MINAMI, P.S. Micologia: métodos laboratoriais de diagnóstico das micoses. São Paulo: Manole, 2003. 199p. MYLONAKIS, E.; CALDERWOOD, S.B. Infective endocarditis in adults. The New England Journal of Medicine, v.345, p.1318-30, 2001.

NAGHETINI, C.C. Caracterização físico-química e atividade antifúngica dos óleos essenciais da Cúrcuma. 2006. 61p. Dissertação (Mestrado em Ciências Farmacêuticas) - Faculdade de Farmácia, Universidade Federal de Minas Gerais, Belo Horizonte. NASCIMENTO, A.C.; RODRIGUES C.S.; ANTONIOLLI, A.R. Atividade antimicrobiana dos óleos essenciais: uma abordagem multifatorial dos métodos. Brazilian Journal of Pharmacognosy, v.17, p.108-13, 2007.

OLIVEIRA, R.A.G. et al. Estudo da interferência de óleos essenciais sobre a atividade de alguns antibióticos usados na clínica. Revista Brasileira de Farmacognosia, v.16, n.1, p.77-82. 2006.

RECIO, M.C.; RIOS, J.L.; VILLAR, A. A review of some antimicrobial compounds isolated from medicinal plants reported in the literature 1978-1988. Phytotherapy Research, v.3, n.4, p.117-25, 1989.

RIOS, J.L.; RECIO, M.C.; VILLAR, A. Screening methods for natural products with antimicrobial activity: a review of the literature. Journal of Ethnopharmacology, v.23, p.127-49, 1998.

RODRIGUES, E.A.C. Infecções hospitalares: prevenção e controle. São Paulo: Sarvier, 1997. 28p.

SANTOS, A.S. et al. Volatile constituents of fruits of Annona glabra L. from Brazil. Flavour and Fragrance Journal, v.13, p.148-50, 1998.

SHANLEY, P.; CYMERIS, M.; GALVÃO, J. Frutíferas da mata na vida amazônica. Belém: [s.n.], 1998. p.91-8.

SOUZA, E.L. et al. Inhibitory action of some essential oils and phytochemicals on the growth of moulds isolated from foods. Brazilian Archives of Biology and Technology, v.48, p.245-50, 2005.

VEIGA JUNIOR, V.F. Controle de qualidade de óleos de copaíba por cromatografia gasosa de alta resolução. 1997. 89p. Dissertação (Mestrado - Área de concentração em Química) - Universidade Federal do Rio de Janeiro, Rio de Janeiro.

VEIGA JUNIOR, V.F.; PINTO, A.C. O gênero Copaifera L. Química Nova, v.25, p.273-86, 2002.

VERGHESE, S.; MULLASARI, A.; PADMAJA, P. Fungal endocarditis cardiac surgery. Indian Heart Journal, v.50, p.418-22, 1998.

WANG HK. The therapeutic potential of flavonoids. Expert Opinion on Investigational Drugs, v.9, p.2103-19, 2000.

Rev. Bras. PI. Med., Botucatu, v.13, n.1, p.1-7, 2011. 